\title{
Trichoscopic findings in androgenetic alopecia and their clinical correlation
}

\author{
Praveena Thiriveedhi ${ }^{{ }^{*}}$, Madhavi Latha Midde ${ }^{2}$, D Masthan Saheb ${ }^{3}$ \\ ${ }^{1}$ Assistant professor, ${ }^{2,3}$ Professor, Department of DVL, Santhiram Medical College and General Hospital, Nandyal A.P, INDIA. \\ Email: dr.praveenakarnati@gmail.com, tpraveenambbs@gmail.com
}

\begin{abstract}
Background: Trichoscopy is the dermoscopic examination of the hair and scalp. It is a fast, non-invasive, and cost-efficient technique that improves diagnostic accuracy and follow-up with hair and scalp disorders. Not much has been published regarding trichoscopy findings in Indian population, despite the great prevalence of androgenetic alopecia(AGA). Aim: To study various trichoscopic patterns of androgenetic alopecia and to correlate the trichoscopic findings clinically. Materials And Methods: 100 androgenetic alopecia patients are included in the study. Clinical, trichoscopic examination is done and photographs are taken. Data is recorded in pre-structured proforma and then tabulated, analysed to get conclusions. Results: Out of 100 AGA patients evaluated, 72 are males and 28 are females. Most of the patients belong to 21-30 years age group in both males and females. Hair dimension diversity, peripilar sign are seen in all grades of AGA. Yellow dots are seen in $47 \%$, white dots in $29 \%$, honey comb pattern in $57 \%$, focal atrichia in $35.7 \%$, empty follicles in $60.7 \%$, multihair follicular unit in $82.1 \%$, hypertrophied sebaceous glands in $77 \%$, and new hair in $82.1 \%$ of AGA patients. Conclusion: Trichoscopy is an easy, noninvasive procedure with both diagnostic and prognostic value in Androgenetic alopecia. Disease severity and activity can be assessed. The images can be easily stored and can be used to compare in the follow up in regard to activity of the disease, efficacy of the treatment. Statistically significant positive correlation is seen between yellow dots, honey comb pattern pigmentation, focal atrichia, empty follicles, hypertrophied sebaceous glands, and advanced stages of male AGA while multihair follicular units, new hair are seen in early stages of AGA of both males and females.

Key Words: Androgenetic alopecia, trichoscopy, peripilar sign, hair dimension diversity
\end{abstract}

\section{*Address for Correspondence:}

Dr Praveena Thiriveedhi, Assistant Professor, Department of DVL, Santhiram Medical College and General Hospital, Nandyal, A.P.

Email: dr.praveenakarnati@gmail.com

Received Date: 04/08/2020 Revised Date: 11/09/2020 Accepted Date: 06/10/2020

DOI: https://doi.org/10.26611/10211624

This work is licensed under a Creative Commons Attribution-NonCommercial 4.0 International License. (cc)) EY-NC

\begin{tabular}{|l|l|}
\hline \multicolumn{2}{|c|}{ Access this article online } \\
\hline Quick Response Code: & Website: \\
& www.medpulse.in \\
& \\
\hline
\end{tabular}

\section{INTRODUCTION}

Androgenetic alopecia(AGA) is a genetically predetermined disorder characterized by progressive loss of terminal hair of the scalp any time after puberty, in a characteristic distribution in both males and females, due to excessive response to androgens. ${ }^{1}$ In AGA, there is stepwise miniaturization of the hair follicle as a result of alteration in the hair cycle dynamics, leading to vellus transformation of terminal hair follicle. ${ }^{2}$ Most accepted grading for male AGA is modified Norwood- Hamilton classification, while in females, it is 3 point Ludwig scale. ${ }^{2}$ Trichoscopy is a novel non-invasive method which allows visualization of hair shafts and scalp at high magnification and performing assessment of the scalp and hair without the need of a scalp biopsy. ${ }^{3}$ Dermoscopic diagnosis of AGA is done by presence of hair dimension diversity, miniaturized follicles. Other signs include honeycomb pigmentation, peripilar brown halo and yellow dots. ${ }^{4}$ Trichoscopy allows measurement and monitoring of hair shaft thickness and helps in calculating the terminal-to-vellus hair ratio in AGA. ${ }^{5}$ Trichoscopy, under higher magnifications, helps to identify and count vellus hairs (with $<0.03 \mathrm{~mm}$ width). In AGA, a predominance of single hairs is seen instead of 2-4 hair shafts observed in normal individuals. ${ }^{6}$ This study is intended to assess the trichoscopic patterns in AGA and to correlate these findings clinically.

\section{MATERIALS AND METHODS}

A prospective, observational study is conducted with 100 patients of Androgenetic alopecia attending OPD of Santhiram trichology centre, Nandyal during a study period of 6 months from October 2019 to March 2020. Ethical clearance is taken from Institutional ethics committee. AGA Patients of age groups ranging from 18 years to 60years, and who are willing to participate in the study are included in the study while patients with other coexistent hair disorders and 
patients already being treated are excluded from the study. Thorough history and clinical examination is done. All the findings are recorded in a pre-structured proforma. Trichoscopy is done using Firefly pro polarizing dermatoscope at magnification of $50 x-70 x$ and the trichoscopic pictures are stored. Frontal, vertex, temporal and occipital areas are examined. The trichoscopic images are assessed by a dermatologist at the time of examination and reevaluated by another dermatologist in photographs on computer. Global photography is done using NIKON 1 J5 VR $10-30 \mathrm{~mm}$ f/3.5-5.6 PD-ZOOM digital camera with resolution of 20.8MP. Later the trichoscopic pictures and global photographs are analysed.

Statistical Analysis

All the data is tabulated and statistical evaluation is done. Chi square test is used to calculate $P$ value and $P$ value of $<0.05$ is considered as significant.

\section{RESULTS}

Out of 100 AGA patients evaluated, 72 are males and 28 are females. In the current study, most of the patients belong to 21-30 years age group in both males and females. The mean age in males is 30.5 years (SD - 9.2) while in female study population, it is 26.4 years (SD - 7.8). 4 have grade 1, 23 have grade 2, 21 have grade 3, 14 have grade 4, 5 have grade 5, 4 have grade 6 and 1 patient has grade 7 Androgenetic alopecia according to Hamilton Norwood grading. In females, have 18 grade 1, 10 have grade 2 Ludwigs female pattern of androgenetic alopecia(FAGA). Most common grade in the current study is grade 2 in males and grade 1 in females.

Trichoscopic findings

Hair dimension diversity, peripilar signs are seen in all grades of AGA. Yellow dots are seen in $47 \%$, white dots in $29 \%$, honey comb pattern in $57 \%$, focal atrichia in $35.7 \%$, empty follicles in $60.7 \%$, multihair follicles in $82.1 \%$, hypertrophied sebaceous glands in $77 \%$, and new hair in $82.1 \%$ of AGA patients.
Miniaturization/ Hair dimension diversity: It is observed in all patients of all grades.

Peripilar sign: It is observed in all patients of AGA in the current study.

Yellow dots: It is seen in 35 patients of male androgenetic alopecia (MAGA) and in 12 patients of FAGA. It is commonly observed in grade 5 and grade 2 in males and in grade 1 female androgenetic alopecia

White dots: It is seen in 23 patients of male androgenetic alopecia and in 6 patients of FAGA. It is commonly observed in grade 6 and 7 in males and in grade 2 in females

Honey comb pattern: It is seen in 42 patients of male androgenetic alopecia and in 15 patients of FAGA. It is commonly observed in grade 6 and 7 in males and in grade 2 in females

Focal Atrichia: It is seen in 32 patients of male androgenetic alopecia and in 10 patients of FAGA. It is commonly observed in grade 6 and 7 in males and in grade 2 females

Empty follicles: It is seen in 55 patients of male androgenetic alopecia and in 17 patients of FAGA. It is commonly observed in grade 6 and 7 in males and in grade 1 females

Multihair follicular unit: It is seen in 46 patients of male androgenetic alopecia and in 23 patients of FAGA. It is commonly observed in grade 1 and 3 in males and in grade 1 females

Hypetrophied sebaceous glands: It is seen in 57 patients of male androgenetic alopecia and in 20 patients of FAGA. It is commonly observed in grade 1,6 and 7 in males and in grade 1 females

New hair: It is seen in 54 patients of male androgenetic alopecia and in 23 patients of FAGA. It is commonly observed in grade 2 and 6 in males and in grade 1 females.

Most common trichoscopic features in male AGA are Hair dimension diversity, peripilar sign followed by Hypertrophied sebaceous glands and empty follicles. In female AGA, most common findings are Hair dimension diversity, peripilar sign followed by Multi hair follicular units.

TABLE 1: TRICHOSCOPIC FEATURES IN MALE AGA

\begin{tabular}{|c|c|c|c|c|c|c|c|c|c|c|c|c|c|c|c|c|c|}
\hline & G 1 & $\%$ & G 2 & $\%$ & G 3 & $\%$ & G 4 & $\%$ & G 5 & $\%$ & G 6 & $\%$ & G 7 & $\%$ & TOTAL & $\%$ & P value \\
\hline FREQUENCY & 4 & 5.5 & 23 & 31.9 & 21 & 29.2 & 14 & 19.4 & 5 & 6.9 & 4 & 5.5 & 1 & 1.4 & 72 & 100 & \\
\hline HDD & 4 & 100 & 23 & 100 & 21 & 100 & 14 & 100 & 5 & 100 & 4 & 100 & 1 & 100 & 72 & 100 & 0.0001 \\
\hline PPS & 4 & 100 & 23 & 100 & 21 & 100 & 14 & 100 & 5 & 100 & 4 & 100 & 1 & 100 & 72 & 100 & 0.0001 \\
\hline YD & 1 & 25 & 12 & 52.2 & 9 & 42.8 & 5 & 35.7 & 3 & 60 & 4 & 100 & 1 & 100 & 35 & 48.6 & 0.0004 \\
\hline WD & 0 & 0 & 7 & 30.4 & 5 & 23.8 & 4 & 28.6 & 2 & 40 & 4 & 100 & 1 & 100 & 23 & 31.9 & 0.21 \\
\hline $\mathrm{HCP}$ & 2 & 50 & 11 & 47.8 & 12 & 57.1 & 9 & 64.3 & 4 & 80 & 3 & 75 & 1 & 100 & 42 & 58.3 & 0.004 \\
\hline EMF & 4 & 100 & 16 & 69.6 & 16 & 76.2 & 12 & 85.7 & 2 & 40 & 4 & 100 & 1 & 100 & 55 & 76.4 & $<0.0005$ \\
\hline MHFU & 3 & 75 & 17 & 73.9 & 16 & 76.2 & 7 & 50 & 2 & 40 & 1 & 25 & 0 & 0 & 46 & 63.8 & $<0.0005$ \\
\hline HSG & 4 & 100 & 17 & 73.9 & 17 & 80.9 & 11 & 78.6 & 3 & 60 & 4 & 100 & 1 & 100 & 57 & 79.2 & $<0.0005$ \\
\hline $\mathrm{NH}$ & 2 & 50 & 19 & 82.6 & 15 & 71.4 & 10 & 71.4 & 4 & 80 & 4 & 100 & 0 & 0 & 54 & 75 & $<0.0005$ \\
\hline
\end{tabular}

Abbreviations: G - grade; HDD - Hair Dimension Diversity; PPS - PeriPilar Sign; YD - Yellow dot; WD - White dot; HCP - Honey comb pattern pigmentation; ATRICHIA - Focal Atrichia; EMF - Empty Follicles; MHFU - Multi hair follicular unit; HSG - Hypertrophied sebaceous gland $\mathrm{NH}-\mathrm{New}$ Hair 
TABLE 2: TRICHOSCOPIC FEATURES IN FEMALE AGA

\begin{tabular}{cccccccc}
\hline GRADE & G 1 & $\%$ & G 2 & $\%$ & TOTAL & $\%$ & P value \\
\hline FREQUENCY & 18 & & 10 & & 28 & & \\
HDD & 18 & 100 & 10 & 100 & 28 & 100 & 0.03 \\
PPS & 18 & 100 & 10 & 100 & 28 & 100 & 0.03 \\
YD & 8 & 44.4 & 4 & 40 & 12 & 42.9 & 0.22 \\
WD & 3 & 16.6 & 3 & 30 & 6 & 21.4 & 1 \\
HCP & 9 & 50 & 6 & 60 & 15 & 53.6 & 0.27 \\
ATRICHIA & 6 & 33.3 & 4 & 40 & 10 & 35.7 & 0.65 \\
EMF & 11 & 61.1 & 6 & 60 & 17 & 60.7 & 0.08 \\
MHFU & 15 & 83.3 & 8 & 80 & 23 & 82.1 & 0.03 \\
HSG & 14 & 77.7 & 6 & 60 & 20 & 71.4 & 0.01 \\
NH & 15 & 83.3 & 8 & 80 & 23 & 82.1 & 0.03 \\
\hline
\end{tabular}

TABLE 3: TRICHOSCOPIC FEATURES IN BOTH MALES AND FEMALES

\begin{tabular}{ccccccc}
\hline & MALES & $\%$ & FEMALES & $\%$ & TOTAL & $\%$ \\
\hline FREQUENCY & 72 & & 28 & & 100 & \\
HDD & 72 & 100 & 28 & 100 & 100 & 100 \\
PPS & 72 & 100 & 28 & 100 & 100 & 100 \\
YD & 35 & 48.6 & 12 & 42.9 & 47 & 47 \\
WD & 23 & 31.9 & 6 & 21.4 & 29 & 29 \\
HCP & 42 & 58.3 & 15 & 53.6 & 57 & 57 \\
ATRICHIA & 32 & 44.4 & 10 & 35.7 & 42 & 42 \\
EMF & 55 & 76.4 & 17 & 60.7 & 72 & 72 \\
MHFU & 46 & 63.8 & 23 & 82.1 & 69 & 69 \\
HSG & 57 & 79.2 & 20 & 71.4 & 77 & 77 \\
NH & 54 & 75 & 23 & 82.1 & 77 & 77 \\
\hline
\end{tabular}

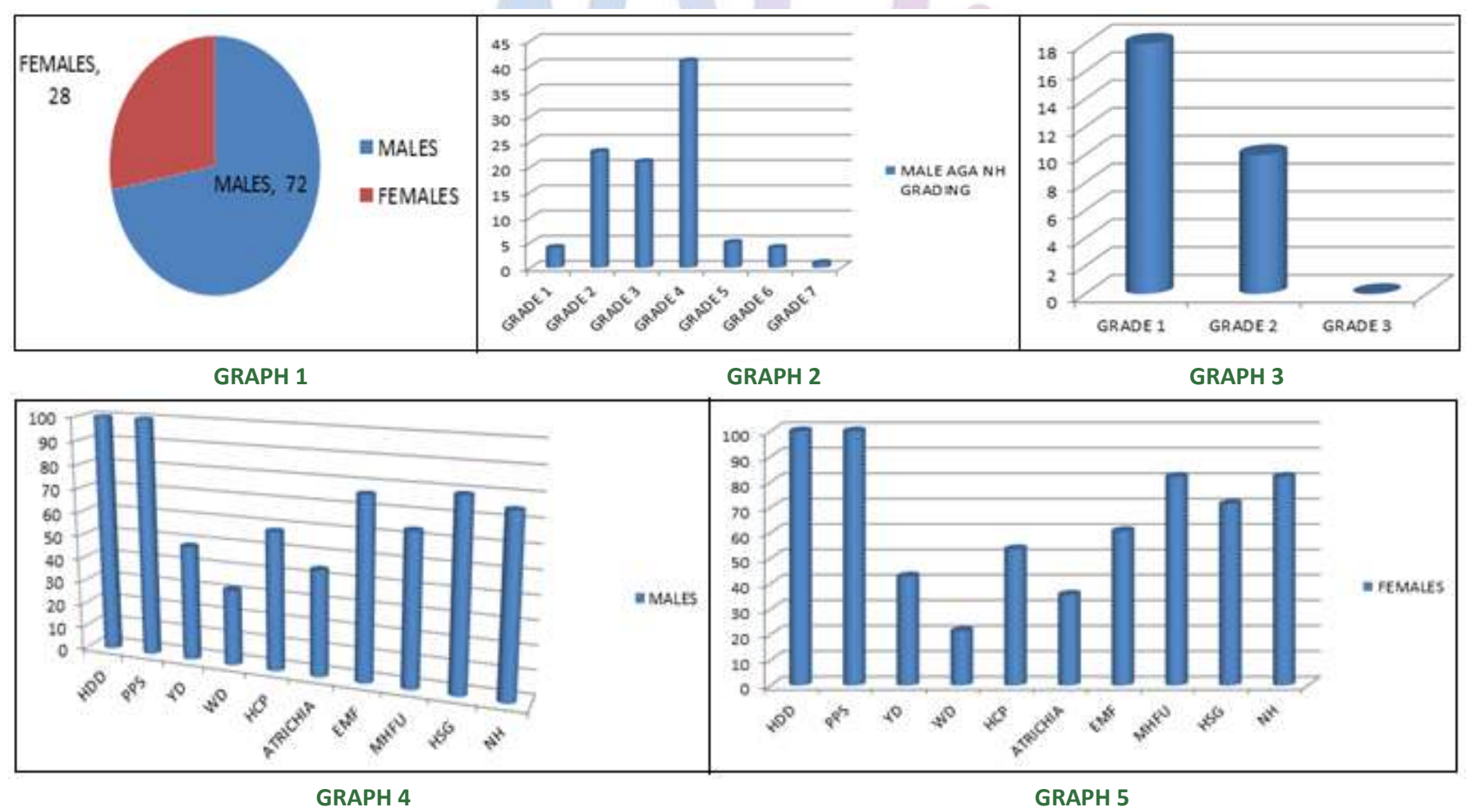




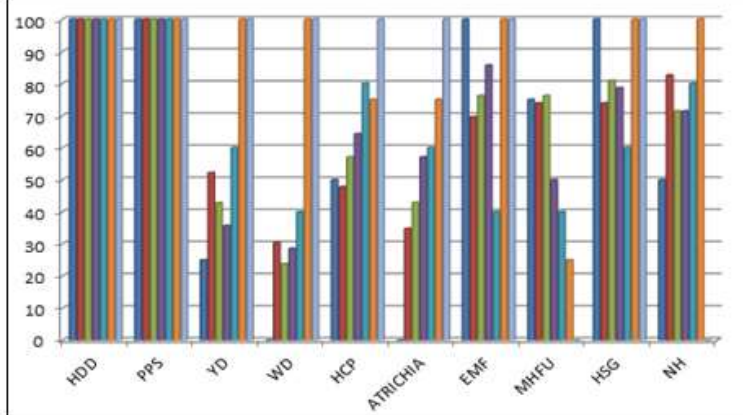

GRAPH 6

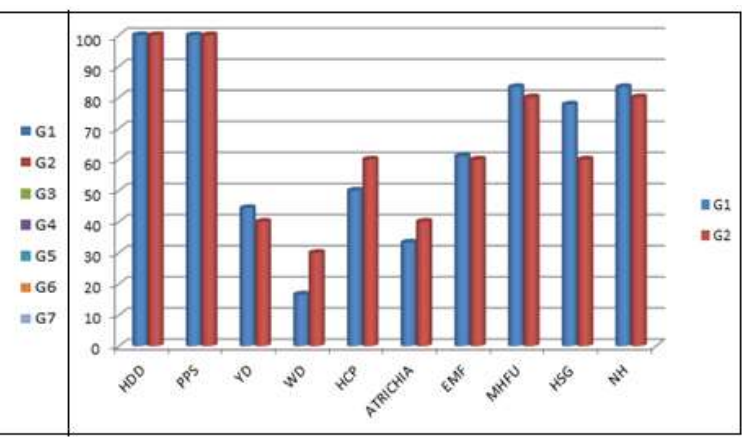

GRAPH 7

Legend:

GRAPH 1: SEX DISTRIBUTION OF POPULATION; GRAPH 2: GRADE WISE DISTRIBUTION IN MALE AGA (NORWOOD HAMILTON GRADING); GRAPH 3: GRADE WISE DISTRIBUTION IN FEMALE AGA ( LUDWIGS GRADING); GRAPH 4: TRICHOSCOPIC FEATURES IN MALE AGA; GRAPH 5: TRICHOSCOPIC FEATURES IN FEMALES; GRAPH 6: TRICHOSCOPIC FEATURES IN MALE AGA GRADE WISE; GRAPH 7: TRICHOSCOPIC FEATURES IN FEMALE AGA GRADE WISE.

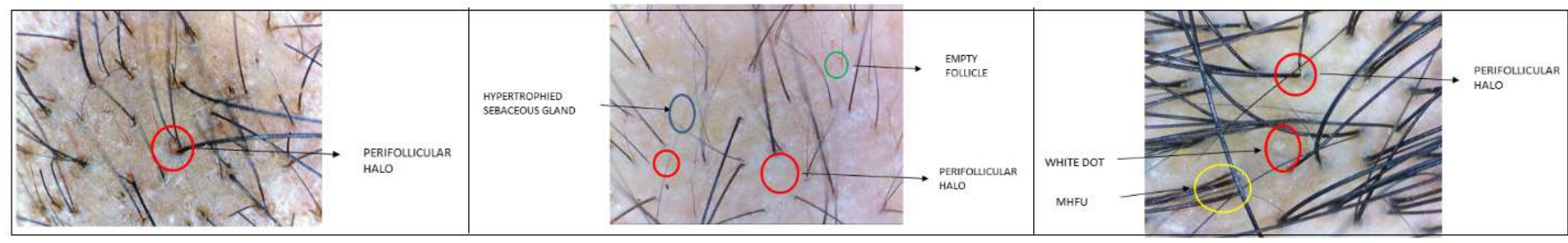

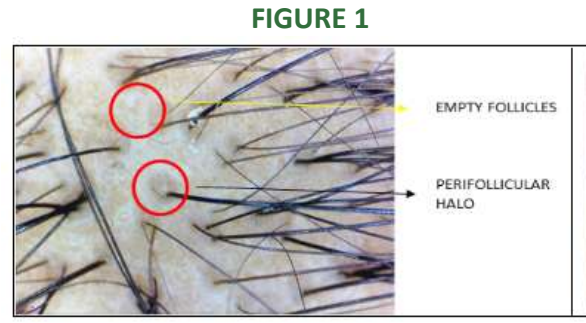

FIGURE 4

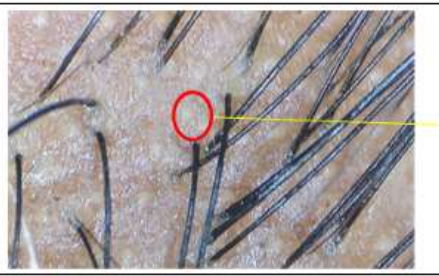

FIGURE 5
FIGURE 3

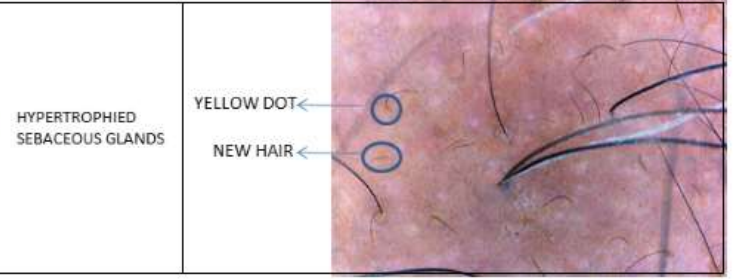

FIGURE 6

FIGURE 1: PERIFOLLICULAR HALO; FIGURE 2: HONEY COMB PATTERN PIGMENTATION WITH HAIR DIMENSION DIVERSITY, HYPERTROPHIED SEBACEOUS GLANDS, EMPTY FOLLICLES, PERIFOLLICULAR HALO; FIGURE 3: MULTIHAIR FOLLICULAR UNITS WITH HONEY COMB PATTERN PIGMENTATION, WHITE DOT, PERIPILAR SIGN; FIGURE 4: EMPTY FOLLICLES, PERIPILAR SIGN; FIGURE 5: HYPERTROPHIED SEBACEOUS GLANDS; FIGURE 6: NEW HAIR WITH YELLOW DOTS

\section{DISCUSSION}

In the present study population of 100,72 are male and 28 are female. In the current study, most of the patients belong to 21-30 years age group in both males and females. The mean age in males is 30.5 years (SD - 9.2) while in female study population, it is 26.4 years (SD - 7.8). This is similar to the study done by Grover ${ }^{7}$ in Indian population where mean age of MAGA was 30-39 years and Krupa Shankar et al.. ${ }^{8}$ with a mean age of $37.05(\mathrm{SD} \pm 6)$ years in MAGA. In a study done by Kibar et al. ${ }^{9}$ the age of the MAGA patients varied from 12 to 75 years (mean, $37.3 \pm 16.6$ years), and that of the FAGA patients varied from 15 to 79 years (mean, $34.3 \pm 15.2$ years). Similarly, in a study by $\mathrm{Hu}$ et $a l .{ }^{10}$ the mean age of MAGA was $30.6(\mathrm{SD} \pm 7.4)$ and FAGA was 35.8 (SD \pm 11.6$)$ years. The most common grade in our study is H-N Grade II 23 cases $(31.9 \%)$. This is similar to a study done by Krupa Shankar et al. ${ }^{8}$ where most common grade in the study was grade II $(27.27 \%)$. While in studies conducted by Ummiti et al.. ${ }^{11}$, Sehgal et al.. ${ }^{12}$, Grover ${ }^{7}$ in Indian population. In a study conducted by Wang et al. ${ }^{13}$ Grade IV was the most common type.

Trichoscopic features:

Hair shaft dimension diversity: AGA results from progressive miniaturization of hair follicles and thus the earliest and diagnostic feature is a hair shaft diameter variation of more than $20 \%$ hair shafts. ${ }^{14}$ In the current study, it is observed in all patients of all grades of AGA. This is in concordance with various studies done by Ummiti et al., Kibar et al., etc.

Peripilar sign: Peripilar sign seen as a subtle brown halo is a specific finding, seen in early stages and reflects perifollicular inflammation. ${ }^{14}$ In the current study, all patients have peripilar sign or peripilar halo. It is similar to Kibar et al.. study (84\%) while in study done by Innui et 
al.., ${ }^{15} 66 \%$ had PPS and in study by Hu et al. ${ }^{10}$, Salahudeen et al.., ${ }^{16}$ PPS was seen in $44.1 \%$ and $51.4 \%$ respectively. Peripilar sign, pathologically corresponds to superficial perifollicular infiltrates composed mainly of lymphocytes. ${ }^{17}$ Perifollicular inflammation is thought to be due to the effect of cosmetics, chemicals, ultraviolet light, mucin deposit, and melanocytes. ${ }^{9}$

Yellow dots: Yellow dots represent follicular infundibulum, distended with degenerating keratinocytes and sebum. ${ }^{18}$ In darker skin shades they may appear pale against the honeycomb pigment. Yellow dots are characteristic of alopecia areata (AA), although can be seen in androgenetic alopecia and other scalp disorders ${ }^{19}$. In androgenetic alopecia, yellow dots are seen in more advanced stages of the disease with a sebaceous component predominance over keratotic elements, differing from the other dermatosis, in which keratinocytic materials are predominant. In AGA, they occur more predominantly in the frontal region compared to the occipital region, have irregular size and distribution, and are less numerous when compared to the amount found in alopecia areata. ${ }^{20}$ In the current study, yellow dots are seen in $48.6 \%$ in males and $42.9 \%$ in females. It is more seen in grade 5, 6 and 7 patients in males. This is statistically significant. While in females, it is seen slightly more in grade 1 in females but not statistically significant. In $\mathrm{Hu}$ et al., study $20.9 \%$ had yellow dots, salahudeen et al. study, $20 \%$, Innui et al., $23.3 \%$ had yellow dots while in kibar et $a l$. , study, it is seen in $68 \%$ patients. In Ummiti et al., study, $91.2 \%$ had yellow dots and the difference is thought to be due to difference in race of study population. White dots: In advanced stages of AGA, follicles can be replaced by connective tissues, afterwards causing atrophy. These empty follicular ostia are seen as WD. WD are more common in the late stages of AGA. ${ }^{21}$ In the current study, $29 \%$ (31.9\% males and $21.4 \%$ females) have white dots. White dots are more commonly seen in stage 5, 6 and 7 in males and in stage 2 in females compared to stage 1 but is statistically not significant. Results of the study are comparable to that of $\mathrm{Hu}$ et al. study and Salahudeen et al. Honey comb pigmentation: In dark-skinned individuals, a perifollicular pigmented network (honeycomb pattern) is usually appreciated over the scalp which is accentuated over sun-exposed areas. ${ }^{22}$ Bald areas and areas with sparse hair, as seen in men with advanced AGA, have a darker pigment network which corresponds to tanning due to excessive sun exposure. This pattern is characterized by grid (irregular lines) and holes. The lines are hyperchromic and represent melanotic reteridges, whereas the holes are the hypochromic suprapapillary epidermis. ${ }^{14}$ In the current study, 57\% (58.3\% males and 53.6\%)had honeycomb pattern pigmentation. Grade 5,6 and 7 in males and grade 2 in males have statistically significant higher incidence of honeycomb pattern of pigmentation. Studies conducted by kibar etal, $\mathrm{Hu}$ et al.., show HCP in $37.3 \%$ and $32.6 \%$ respectively. The difference may be explained by the difference in the sun exposure and racial difference. While an Indian study by Ummiti et al.. showed a higher incidence of HCP $85.7 \%$. Focal Atrichia: Focal atrichia is the finding of small $4 \mathrm{~mm}$ diameter areas in the scalp devoid of emerging hairs. It is clinical clue to the diagnosis of female pattern hair loss, particularly the late onset subtype $^{23}$ Zhang et al. claimed that there is positive correlation between focal atrichia and stage of hair loss. ${ }^{24}$ In the current study, focal atrichia is seen in $42 \%$ ( $44.4 \%$ males and $35.7 \%$ females) patients. Focal atrichia is seen in grade 5,6, and 7 significantly in higher percent individuals than early stages of AGA in males while grade 2 females have higher incidence than grade 1 females but is not statistically significant. The present study findings of positive correlation of atrichia with advanced stages are similar to the studies by $\mathrm{Hu}$ et al., and Zhang et al. Empty follicles: Empty follicles are seen dermocopically as skincolored small depressions without hairs. They correspond to an empty infundibula. ${ }^{19}$ In the current study, empty follicles are seen in $72 \%$ ( $76.4 \%$ in males and $60.7 \%$ in females) patients of AGA. Multihair follicular units: $\geq 3$ hairs from lunit without any epidermal and peripilar sign is regarded as MHFU. It is related to less severe AGA in males and females. In early AGA, dermal and perifollicular inflammation constituting growth factors and cytokines, together with the anabolic effects of testosterone, may provoke this augmentation. In the current study, MHFU are seen in 69\% ( 63.8\% in males and $82.1 \%$ in females) AGA patients. In Kibar et al.. study, $60.3 \%$ males and 56\% females had MHFU while Salahudeen et al.. study, $43.5 \%$ had MHFU.

Hypertrophied sebaceous glands: These are represented by pearly white dots (papules) in long standing cases of AGA. ${ }^{14}$ In AGA, the 5- $\alpha$-reductase activity stimulates sebaceous glands and causes hypertrophy. ${ }^{9}$ In the present study, hypertrophied sebaceous glands are seen in $77 \%$ individuals (79.2\% males and $71.4 \%$ females). In this study, HSG are seen even in early stages of AGA in both males and females.

New hair: short, thick, regrowing terminal hair/ new hair is seen in $77 \%$ ( $75 \%$ males and $82.1 \%$ females) of AGA patients. New hair are seen less in advanced stages of AGA in both males and females. This is statistically significant.

\section{CONCLUSIONS}

Trichoscopy is an easy, noninvasive procedure with both diagnostic and prognostic value in Androgenetic alopecia. Disease severity and activity can be assessed. The images can be easily stored and can be used to compare in the follow up in regard to activity of the disease, efficacy of the treatment. This current study concludes that hair 
dimension diversity, peripilar sign are important indicators of AGA present in all grades in both males and females. There is statistically significant increase in yellow dots, honey comb pattern of pigmentation, focal atrichia, empty follicles, hypertrophied sebaceous glands in advanced stages of AGA while multihair follicular units, new hair are significantly seen in early stages of AGA. White dots are seen more in advanced stages but are not statistically significant. In female AGA, Multihair follicular units, new hair are significantly seen in Ludwigs grade 1 . There is no statistically significant difference in both Ludwig grades in terms of honey comb pattern, focal atrichia, empty follicles.

\section{REFERENCES}

1. Sasaki GH. Review of Human Hair Follicle Biology: Dynamics of Niches and Stem Cell Regulation for Possible Therapeutic Hair Stimulation for Plastic Surgeons. Aesthetic Plast Surg. 2019 Feb;43(1):253-266

2. Kaliyadan F, Nambiar A, Vijayaraghavan S. Androgenetic alopecia: An update. Indian J Dermatol Venereol Leprol 2013;79:613-25.

3. Al-Refu K. Clinical significance of trichoscopy in common causes of hair loss in children: Analysis of 134 cases. Int J Trichol 2018;10:154-61.

4. Ramos LD, Santili MCN, Bezerra FC, Ruiz MFMA, Petri V, Patriarca MT. Dermoscopic findings in female Androgenetic alopecia. An Bras Dermatol. 2012;87(5):691-4.

5. Rudnicka L, Olszewska M, Rakowska A, KowalskaOledzka E, Slowinska M. Trichoscopy: a new method for diagnosing hair loss. J Drugs Dermatol 2008; 7:651-654.

6. Deloche $\mathrm{C}$, de Lacharrière $\mathrm{O}$, Misciali $\mathrm{C}$, Piraccini BM, Vincenzi C, Bastien $\mathrm{P}$, et al. Histological features of peripilar signs associated with androgenetic alopecia. Arch Dermatol Res 2004; 295:422-428.

7. Grover S. A study of patterns of androgenetic alopecia in men: An Indian perspective. $\mathrm{Br} \mathrm{J}$ Dermatol. 2005;152:572-4.

8. Krupa Shankar D, Chakravarthi M, Shilpakar R. Male androgenetic alopecia: Population-based study in 1,005 subjects. Int J Trichology. 2009;1:131-3

9. Kibar M, Aktan S, Bilgin M. Scalp dermatoscopic findings in androgenetic alopecia and their relations with disease severity. Ann Dermatol. 2014;26(4):478-484.
10. $\mathrm{Hu} \mathrm{R}, \mathrm{Xu} \mathrm{F}$, Han $\mathrm{Y}$, Sheng $\mathrm{Y}$, Qi S, Miao Y, et al. Trichoscopic findings of androgenetic alopecia and their association with disease severity. J Dermatol. 2015;42 : 602-7.

11. Ummiti A, Priya PS, Chandravathi PL, Kumar CS. Correlation of Trichoscopic Findings in Androgenetic Alopecia and the Disease Severity. Int $J$ Trichology. 2019;11(3):118-122.

12. Sehgal VN, Kak R, Aggarwal A, Srivastava G, Rajput P. Male pattern androgenetic alopecia in an Indian context: A perspective study. J Eur Acad Dermatol Venereol. 2007;21:473-9

13. Wang TL, Zhou C, Shen YW, Wang XY, Ding XL, Tian $\mathrm{S}$, et al. Prevalence of androgenetic alopecia in china: A community-based study in six cities. Br J Dermatol. 2010;162:843-7.

14. Jain N, Doshi B, Khopkar U. Trichoscopy in alopecias: Diagnosis simplified. Int J Trichol 2013;5:170-8.

15. Inui $\mathrm{S}$, Nakajima $\mathrm{T}$, Itami $\mathrm{S}$. Scalp dermoscopy of androgenetic alopecia in Asian people. J Dermatol 2009;36(2):82-5.

16. Salahudeen M, Menon R, David B. Trichoscopic study of non-scarring alopecia of the scalp. J. Evolution Med. Dent. Sci. 2017;6(68):4894-4898

17. Deloche C, de Lacharriere O, Misciali C, et al. Histological features of peripilar signs associated with androgenetic alopecia. Arch Dermatol Res 2004;295(10):422-8.

18. Tosti A, Duque-Estrada B. Dermoscopy in hair disorders. J Egypt Womens Dermatol Soc 2010;7:1-4

19. Oriol Yélamos, Ralph Braun, Daniel Morgado, Constanza Riquelme Mc Loughlin. Correlation of trichoscopy (hair and scalp dermoscopy). dermoscopedia. June 14, 2019,

20. Lima CS, Lemes LR, Melo DF. Yellow dots in trichoscopy: relevance, clinical significance and peculiarities. An Bras Dermatol. 2017; 92(5):724-6.

21. Ross EK, Vincenzi C, Tosti A. Videodermoscopy in the evaluation of hair and scalp disorders. J Am Acad Dermatol 2006; 55: 799-806.

22. Melike Kibar (May 3rd 2017). Trichoscopy and Trichogram, Hair and Scalp Disorders, Zekayi Kutlubay and Server Serdaroglu, IntechOpen, DOI: 10.5772/66836

23. Olsen EA, Whiting DA. Focal atrichia: A diagnostic clue in female pattern hair loss. J Am Acad Dermatol. 2019 Jun;80(6):1538-1543.e1.

24. Zhang X, Caulloo S, Zhao Y, Zhang B, Cai Z, Yang J, et al. Female pattern hair loss: Clinico-laboratory findings and trichoscopy depending on disease severity. Int $\mathrm{J}$ Trichology. 2012;4:23-8

\section{Source of Support: None Declared Conflict of Interest: None Declared}

\section{Policy for Articles with Open Access:}

Authors who publish with MedPulse International Journal of Medicine, Print ISSN: 2550-7583, Online ISSN: 2636-4751 agree to the following terms: Authors retain copyright and grant the journal right of first publication with the work simultaneously licensed under a Creative Commons Attribution License that allows others to share the work with an acknowledgement of the work's authorship and initial publication in this journal.

Authors are permitted and encouraged to post links to their work online (e.g., in institutional repositories or on their website) prior to and during the submission process, as it can lead to productive exchanges, as well as earlier and greater citation of published work. 